\title{
O potencial bioenergético dos resíduos provenientes do beneficiamento da biomassa
}

\section{cafeeira}

The bioenergetic potential of waste arising from the benefit of coffee biomass

El potencial bioenergético de los residuos derivados del beneficio de la biomasa del café

Recebido: 21/02/2021 | Revisado: 28/02/2021 | Aceito: 01/03/2021 | Publicado: 02/03/2021

\author{
Alline Maria Trancoso Ferraz Silva David \\ ORCID: https://orcid.org/0000-0003-4860-3946 \\ Centro Universitário UniFTC, Brasil \\ E-mail: allinetrarquitetura@gmail.com \\ Jerisnaldo Matos Lopes \\ ORCID: https://orcid.org/0000-0002-3921-3631 \\ Universidade do Estado da Bahia, Brasil \\ E-mail: jerislopes@hotmail.com
}

\begin{abstract}
Resumo
A pesquisa faz uma abordagem sobre a biomassa cafeeira, que é uma fonte de bioenergia de grande relevância econômica para o país, maior produtor de grãos beneficiados do mundo. A palha de café é um resíduo do cultivo cafeeiro com alto potencial devido à possibilidade de retorno ao solo de grande parte dos nutrientes absorvidos durante a formação dos frutos. Nessa perspectiva o objetivo do presente estudo é compreender o potencial bioenergético dos resíduos provenientes do beneficiamento da biomassa cafeeira. Para observar a propriedade, descrever o beneficiamento e estudar o potencial bioenergético do resíduo do café, a metodologia utilizada foi de natureza aplicada, abordagem qualitativa e, para atingir o objetivo foi utilizada pesquisa bibliográfica exploratória e pesquisa a campo. Como resultado pode-se afirmar que a palha proveniente do processo de beneficiamento da biomassa cafeeira é devolvida ao solo como adubo orgânico o que consequentemente diminui os custos com a adubação química e favorece a sustentabilidade no meio rural. Na fase de implantação da lavoura cafeeira a utilização da palha constitui-se em fonte de nutrientes e matéria orgânica. Neste contexto, o estudo apresenta o conceito e aproveitamento dessa fonte de bioenergia e aspectos importantes da biomassa do café como sua estrutura e etapas do beneficiamento. Contudo, com o presente estudo foi possível constatar que a biomassa cafeeira se constitui uma importante fonte bioenergética.
\end{abstract}

Palavras-chave: Biomassa; Beneficiamento do café; Bioenergia.

\begin{abstract}
The research approaches the coffee biomass, which is a source of bioenergy of great economic relevance for the country, the largest producer of processed grains in the world. Coffee straw is a residue from coffee cultivation with high potential due to the possibility of returning most of the nutrients absorbed during fruit formation to the soil. In this perspective, the objective of this study is to understand the bioenergetic potential of residues from the processing of coffee biomass. To observe the property, describe the processing and study the bioenergetic potential of the coffee residue, the methodology used was of an applied nature, qualitative approach and, to reach the objective, exploratory bibliographic research and field research were used. As a result, it can be said that the straw from the coffee biomass processing process is returned to the soil as organic fertilizer, which consequently reduces the costs of chemical fertilization and favors sustainability in rural areas. In the implementation phase of the coffee plantation, the use of straw constitutes a source of nutrients and organic matter. In this context, the study presents the concept and use of this source of bioenergy and important aspects of coffee biomass as its structure and processing stages. However, with the present study it was possible to verify that coffee biomass is an important bioenergetic source.
\end{abstract}

Keywords: Biomass; Coffee processing; Bioenergy.

\section{Resumen}

La investigación aborda la biomasa del café, que es una fuente de bioenergía de gran relevancia económica para el país, el mayor productor de granos procesados del mundo. La paja de café es un residuo del cultivo del café con alto potencial debido a la posibilidad de devolver al suelo la mayoría de los nutrientes absorbidos durante la formación del fruto. En esta perspectiva, el objetivo de este estudio es comprender el potencial bioenergético de los residuos del procesamiento de la biomasa de café. Para observar la propiedad, describir el procesamiento y estudiar el potencial bioenergético del residuo de café, la metodología utilizada fue de carácter aplicado, enfoque cualitativo y, para alcanzar el objetivo, se utilizó investigación bibliográfica exploratoria e investigación de campo. Como resultado, se puede decir que la paja del proceso de procesamiento de la biomasa del café se devuelve al suelo como fertilizante orgánico, lo que en consecuencia reduce los costos de la fertilización química y favorece la sostenibilidad en las zonas rurales. En la fase de implementación del cafetal, el uso de paja constituye una fuente de 
nutrientes y materia orgánica. En este contexto, el estudio presenta el concepto y uso de esta fuente de bioenergía y aspectos importantes de la biomasa del café como su estructura y etapas de procesamiento. Sin embargo, con el presente estudio se pudo verificar que la biomasa del café es una fuente bioenergética importante.

Palabras clave: Biomasa; Procesamiento de café; Bioenergía.

\section{Introdução}

O presente artigo é fruto da dissertação de mestrado que conecta a arquitetura paisagística e a bioenergia através do arranjo físico da Biomassa Cafeeira. As energias provenientes do processo de milhões de anos de decomposição orgânica, como o petróleo, por exemplo, não são renováveis, o que instiga a pesquisa por fontes alternativas de energia limpa. Uma das questões mais importantes nesta busca é a investigação de estratégias para substituição da energia elétrica e diminuição das emissões de poluentes, o que vem fortalecendo as fontes de energia alternativas. Uma das maneiras de se obter energia de fonte renovável é por meio do aproveitamento de biomassa como, por exemplo, a casca ou palha do café. Biomassa pode ser definida como toda matéria orgânica renovável que existe. A utilização da biomassa como fonte bioenergética pode ser feita de diversas formas, desde combustão direta, processos termoquímicos ou de processos biológicos como, por exemplo, o uso da palha do café como adubo. Sendo o Brasil o maior produtor mundial de café e consequentemente nas lavouras de café o final do processo de beneficiamento gera uma grande quantidade de resíduos, a casca ganha uma grande importância para um desenvolvimento energético sustentável (Orsini, 2012).

Diante do exposto, a partir do conhecimento sobre de destinação da casca nas lavouras de café, é possível afirmar que existe potencial bioenergético dos resíduos provenientes do beneficiamento da biomassa cafeeira?

O objetivo deste artigo é estudar o potencial bioenergético dos resíduos provenientes do beneficiamento da biomassa cafeeira, para tanto, é necessário percorrer um percurso metodológico para alcançar os objetivos. O Café estudado é premiado e possui características singulares, fato que instiga e ratifica o interesse pela pesquisa do beneficiamento da biomassa que dá origem ao café gourmet.

\section{Metodologia}

Neste trabalho, os procedimentos técnicos utilizados foram pesquisa bibliográfica exploratória com abordagem qualitativa e pesquisa de campo. É necessário decidir qual tipo de procedimento será utilizado na execução da pesquisa a fim de alcançar os objetivos indicados. A revisão de literatura e a observação de campo foram cruciais para discorrer sobre o processo produtivo abarcando os equipamentos envolvidos no beneficiamento da biomassa do café até a destinação da casca (Pereira, et al, 2018).

Após esse levantamento, foi realizada a revisão da literatura onde, nos livros e artigos, foram encontrados diferentes tipos de estudos que embasaram esta pesquisa, a qual é de natureza exploratória com abordagem qualitativa. A escolha pela Revisão de literatura se deu, por essa ser uma atividade para localizar e consultar fontes diversas de informações tendo como objetivo coletar mais dados a respeito do tema. A consulta em livros, periódicos, teses, dissertações e demais documentos escritos, os dados necessários para avançar na investigação do assunto de interesse do pesquisador (Gil, 2010).

A pesquisa de campo possibilitou a coleta de dados para compreensão do processo produtivo do beneficiamento do café e a destinação da casca. Além disso, os dados do locus de pesquisa e de produtividade da cultura do café foram obtidos no Instituto Brasileiro de Geografia e Estatística (IBGE, 2019).

O estudo de campo caracteriza-se pelas investigações que priorizam o aprofundamento das questões propostas a distribuição das propriedades da população segundo determinadas variáveis, utilizando muito mais técnicas de observação do que interrogação (Gil, 2010).

Barra do Choça, está situada no interior da Bahia, na região Sudoeste do Estado. Através da BA-265, está a 27 km de 
Vitória da Conquista que é uma área de entroncamento rodoviário atravessada por três importantes rodovias: a BR-116 (interliga norte e sul do país), a BA-262 (acesso ao leste e oeste da Bahia) e a BA-415 (acesso à BR-101 e ao litoral sul do Estado), essa localização estratégica favorece a articulação e a logística para o comércio e exportação da produção agrícola. Sua intensa urbanização foi acelerada pelo programa do governo federal da década de 1970, que destinou vultuosos recursos financeiros para estimular a lavoura cafeeira implementada na região (Ferraz, 2001).

A observação de campo foi realizada na Fazenda Viçosa, localizada no referido município. Com relação à população estimada, Barra do Choça, segundo dados do Instituto Brasileiro de Geografia e Estatística (IBGE) em 2019 era de 31.603 habitantes. Sua área é de $765,152 \mathrm{~km}^{2}$. É nesse cenário que a propriedade beneficia a biomassa do café e contribuiu como campo de estudo para a referida pesquisa.

$\mathrm{Na}$ etapa de pesquisa de campo, aconteceram duas visitas as fazendas, a fazenda Vidigal, onde ocorre a colheita e a fazenda Viçosa, sede do beneficiamento. A primeira oportunidade foi no Encontro Nacional do café, realizado em Maio de 2019, momento em que foram conseguidos elementos fundamentais para maior compreensão do estudo da implantação da lavoura, características edafoclimáticas, manejo do cafezal, assim como, foi a chance de acompanhar uma colheitadeira em ação. Na segunda visita foi possível analisar os diversos talhões da lavoura em outra fase de amadurecimento.

Depois do levantamento documental, e observação de campo, o proprietário e responsável técnico pelo cafezal, relatou o processo de beneficiamento através da entrevista livre que foi utilizada para obter os dados necessários para o sucesso da referida pesquisa.

A análise dos resultados foi feita por meio da revisão de literatura e, mesmo em face às limitações da pandemia, os proprietários da fazenda, colaboraram de forma ímpar para que a conclusão do estudo fosse possível, ao disponibilizar dados de modo remoto.

\section{Resultados e Discussão}

O cafeeiro é uma planta cuja fruta possui no seu interior o grão com o endosperma mais o embrião numa massa compacta. A semente é envolvida pelo pergaminho ou endocarpo, uma película interna e a mucilagem. A seguir vem a polpa, uma camada carnuda que fica logo abaixo da casca (Lima, 2010)

O café é composto pelo grão (endosperma + embrião), que é envolvido por uma membrana transparente chamada tegumento, depois pelo pergaminho (ou endocarpo), por uma camada de pectina (ou mucilagem), pela polpa (ou mesocarpo) e, por fim, pela casca (ou pericarpo). Após o despolpamento da cereja do café, o grão de café é separado do mesocarpo e pericarpo que em conjunto compõem a palha de café.

No agronegócio cafeeiro, quando restos de colheitas são desprezados de modo inadequado, podem causar poluição e degradação dos solos e águas e deixam de ser aproveitados como fonte de renda extra ou economia de aditivos químicos. Nesse contexto o café compõe uma importante fonte de biomassa que, na atualidade oferece uma gama de possibilidades para reduzir a dependência por combustíveis fósseis e consequente diminuição na emissão de gases na atmosfera (Orsini, 2012).

As pesquisas mostraram que o café chegou ao Brasil em 1727 e devido às condições climáticas brasileiras, o cultivo de café se desenvolveu em larga escala para suprir o mercado nacional. Com a "Crise de 29", milhões de pés de café foram arrancados e sacas incendiadas como forma de tentar estacionar a queda dos preços. Quando a economia se recuperou, a exportação do café voltou a ser como antes. (Nova, 2010).

De acordo com a Empresa Brasileira de Pesquisa Agropecuária (EMBRAPA), a produção de café em nível mundial no ano cafeeiro-2018-2019 atingiu 174,5 milhões de sacas de 60kg (Ferreira, 2019).

O Brasil é o maior exportador de café no mercado mundial e ocupa a segunda posição, entre os países consumidores da bebida. O que torna o país consequentemente o maior produtor mundial de casca de café. Conforme dados do Instituto 
Brasileiro de Geografia e Estatística (IBGE) a safra de café Arábica cresceu entre o ano de 2019 e 2020 e teve um crescimento maior em produção do que em área plantada como mostra o Quadro 1.

Quadro 1 - Área, Produção e Rendimento Médio.

\begin{tabular}{|c|c|c|c|c|c|c|c|c|}
\hline \multicolumn{7}{|c|}{ Safra de Café Arábica (em grão) 2019 e das estimativas para 2020 Brasil. } \\
\hline \multicolumn{3}{|c|}{ Área (ha) } & \multicolumn{3}{c|}{ Produção (t) } & \multicolumn{3}{c|}{ Rendimento Médio (kg/ha) } \\
\hline 2019 & 2020 & Var \% & 2019 & 2020 & Var \% & 2019 & 2020 & Var \% \\
\hline 1430879 & 1513039 & 5.7 & 2072728 & 2550105 & 23.0 & 1449 & 1685 & 16.3 \\
\hline
\end{tabular}

Fonte: Adaptado pelos autores com base no IBGE, Diretoria de Pesquisas, Coordenação Agropecuária, Levantamento Sistemático da Produção Agrícola, Maio, 2020.

A partir da década de 1970, as inovações tecnológicas da chamada "Revolução Verde" disseminaram-se por vários países, dentre eles o Brasil, alterando definitivamente a produção agrícola. O uso de novas sementes acompanhado de modernas técnicas e maquinários agrícolas aumentaram consideravelmente a produção (Andrade, 1994).

A Cafeicultura da Bahia é reconhecida pelos cafés especiais super premium e cafés comerciais de valor mais competitivo. A Chapada Diamantina produz quatro dos dez melhores cafés do Brasil, dentre os municípios se destaca Piatã, a 1.300 metros de altitude e variáveis climáticas que viabilizam a produção de um grão de excelência. O café gourmet de Piatã é reconhecido como verdadeiro tesouro (Nova, 2010).

No processo de beneficiamento do café na região do Planalto da Conquista, depois de colhido o fruto é lavado, selecionado, descascado, despolpado e seco em estufa ou secadores dentro da propriedade ou então são levados para Caatinga para secar ao vento em terreiros de chão batido em regiões semiáridas, conhecidas pelo bioma da "Caatinga" de Anagé, José Gonçalves, Bate Pé ou Boa Nova na Bahia (Bacelar, et al, 2020).

Com a observação de campo, foi possível elaborar o Quadro 2 que resume o processamento do beneficiamento do café até a comercialização e a posteriori todas as etapas estão descritas e explicadas: 
Quadro 2 - Etapas de pós-colheita do café.

\begin{tabular}{|c|c|c|}
\hline Etapa & Sub etapas & Função \\
\hline \multirow{4}{*}{ 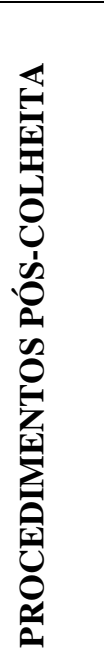 } & SECAGEM & $\begin{array}{l}\text { A secagem é feita na fazenda Viçosa por secadores mecânicos, utilizando } \\
\text { a secagem lenta e com descanso programado para uniformização da } \\
\text { umidade entre os grãos. }\end{array}$ \\
\hline & ARMAZENAGEM & Armazenamento é feito em tulhas para descanso do café. \\
\hline & BENEFICIAMENTO & $\begin{array}{l}\text { O beneficio da biomassa do café é realizado na fazenda Viçosa por uma } \\
\text { máquina apropriada e depois por uma mesa densimétrica para seleção dos } \\
\text { melhores grãos. }\end{array}$ \\
\hline & COMERCIALIZAÇÃO & $\begin{array}{l}\text { A comercialização é feita por corretores privados e pela Cooperativa: a } \\
\text { COOPMAC. }\end{array}$ \\
\hline
\end{tabular}

Fonte: Autoria própria, conforme dados obtidos na dissertação de mestrado, 2020.

Na propriedade observada, o processo de beneficiamento da biomassa do café inicia na via úmida, através da lavagem e posterior separação dos frutos secos, dos verdes e dos maduros, através do despolpamento. A partir de então, inicia-se o processo de fermentação desejada, fazendo um café "Full Washed" - Café despolpado. Depois dessa etapa inicia a fase da via seca, ou seja, a secagem do café. O café é levado aos secadores mecânicos e após uma seca lenta em torno de $72 \mathrm{hs}$, não ultrapassando a temperatura de $35^{\circ}$ e é armazenado em tulhas. Posteriormente, é descascado ou beneficiado para futura comercialização.

No início do beneficiamento, a biomassa do café é despejada em uma moega (espaço grande para recebimento do café) e embaixo dela há uma esteira que leva o café a uma altura maior para cair em uma peneira que retira um pouco de folhas e galhos de café seco, e depois esse café cai em um lavador. A função do lavador é lavar e separar os frutos por densidade, o fruto de café seco boia e segue para o destino reto, o fruto de café maduro e verde afunda (por ser mais denso) e muda de local. Ao mudar de posição o fruto de café que afunda recebe um jato de água por baixo e se eleva, saindo pela parte de cima e cai em um elevador.

Ao final desse processo foi separado o "café boia" que é o café seco e está em outro destino, um café que naturalmente já perdeu qualidade e os outros dois cafés, o verde e o maduro, sobem pelo elevador e em uma altura de 7 metros, cai em um compartimento, denominado despolpador, que separa o maduro do verde. Esse estágio consegue descascar o maduro por pressão e o café verde por não ter a casca solta do grão, não descasca. O café verde é então direcionado pelas laterais, e assim o café verde é quase totalmente separado, alguns chegam a 100\% de separação nessa etapa. Deste modo, o café maduro com a mucilagem cai com a casca em outro compartimento, que tem um descascador que separa a casca dos grãos, chegando a semente que é o produto final.

Esse café é direcionado para um tanque de 5.000L, ao cair, é adiciona aos poucos uma enzima - uma proteína que acelera o processo de retirada dessa mucilagem (composta de açucares e que confere toda a qualidade do café). A retirada da mucilagem é fundamental para evitar a fermentação do café e por consequência estragar a bebida. Durante o processo de maturação o grão já absorveu as propriedades e quando o fruto começa a murchar, o café já atingiu o ápice da maturação, então 
é necessário o ponto de cereja para iniciar o processo adequado e conferir a característica que dá ao café Vidigal uma qualidade única.

Quando o tanque encontra-se cheio, o café permanece até o dia seguinte, quando se abre um registro e o café sai por um cano e cai numa centrifuga que retira a mucilagem. Posteriormente o café cai em um terreiro e depois é retirado para o secador.

Os secadores são equipamentos que podem ser verticais ou horizontais, a fazenda utiliza seis secadores horizontais em cilindro e um secador vertical. Um deles menor (5.000 l), uma vez que, quando se inicia a colheita o volume de café a secar é pequeno e depois é colocado no grande $(15.000$ l) até completar. Esses secadores rodam e recebem ar quente da fornalha. Através de um ventilador potente é lançado ar quente constante dentro da massa do café, ao mesmo tempo ele gira para que esse ar, que é introduzido no meio do cilindro se espalhe e a seca aconteça de forma homogênea.

Depois dessa seca que dura entre de 72 a 80 horas, o café despolpado e seco vai para uma máquina de benefício, onde é retirado o pergaminho, que é a ultima casca do café. A máquina retira a casca. Nessa etapa acontece a primeira seleção separando um pouco de grãos quebrados e menores e na sequencia cai em outra máquina, a densimétrica. Nessa etapa é separado o café bica 1, bica 2 e bica 3, em 3 compartimentos. Nesse contexto é separado o café melhor, com os grãos mais perfeitos.

Se a colheita for realizada com a máquina o processo é o mesmo, com a diferença que não precisa esperar recolher todo o café para levar para o beneficiamento. A fazenda dispõe de um trator com uma carreta a espera da máquina, que ao finalizar a colheita e encher a carreta, vai para o mesmo lugar onde o café é transferido para moega e segue o fluxo idêntico ao relatado na coleta manual.

A casca do café é devolvida ao solo através da decomposição orgânica, por sua vez é transformada em adubo sendo novamente absorvida pela planta mantendo o ciclo sadio para o desenvolvimento da biomassa do café. Não se deve deixar de aproveitar a biomassa gerada pelo beneficiamento do café por meio da casca e também com a água residuária gerada no processo de despolpamento. A fazenda Viçosa utiliza um sistema de recirculação da água no processo de despolpamento, com os tanques de decantação em série, depois de atingir o último tanque, retorna-se com a água ao sistema. Durante todo o período da despolpa do café esse processo se repete.

A economia de água relatada é de $85 \%$ comparado a técnica sem recirculação. A água do processo é aplicada na lavoura no dia seguinte, sendo distribuída por um tanque conduzido pelo trator e ela é lançada no solo, com uma quantidade apropriada para cada planta. Esse processo ao mesmo tempo irriga a lavoura, aproveita o potássio, elemento essencial e caro para a produção do café, presente com altos teores no resíduo da biomassa da casca do café.

Na sequencia o café é pesado, acondicionado em sacos de juta de $60,5 \mathrm{~kg}$, no qual é feita uma costura, e por fim, o café está pronto para ser levado ao caminhão e destinado para a cooperativa. Esse é todo o fluxo do beneficiamento do café que acontece na fazenda Viçosa onde o café já seco é embalado em sacos para ser vendido onde exista demanda pelo produto.

$\mathrm{Na}$ lavoura cafeeira, o beneficiamento do fruto gera uma grande quantidade de resíduos, principalmente a casca de café. O café é fonte de biomassa através da palha e esse resíduo pode retornar ao solo onde boa parte dos nutrientes é absorvida durante o desenvolvimento de novos frutos. Aproveitando no solo a palha do café, os cafeicultores obtêm diminuição dos gastos com adubação química, uma vez que esse resíduo é rico em nutrientes como nitrogênio e potássio.

Nas fazendas de café a casca atua como principal fonte de adubo orgânico. A palha de café comum, contem cerca de $1,5 \%$ de N, 0,15\% de P e 3,0 \% de K, além de cálcio, magnésio, enxofre e micro-nutrientes. A melhor estratégia para o aproveitamento da palha é quando, à medida que o café vai sendo beneficiado, esse resíduo já retorna para lavoura e é distribuído entre os pés de café. (Matiello, 2016). 
Uma escolha apropriada no reaproveitamento do resíduo da produção do café é o uso na compostagem, as cascas podem ser utilizadas diretamente como cobertura do solo, sendo uma boa opção para solos que apresentem carência em potássio, e seu uso é adequado para variados tipos de culturas, incluindo a própria cafeicultura. As cascas de café são ricas em potássio e outros nutrientes minerais, o que permite serem empregadas como um fertilizante orgânico, não sendo necessário nenhum processamento na mesma, ou seja, pode ser empregada direto no solo, além disso, as cascas utilizadas como compostagem favorecem o controle da erosão, o que diminui a perda de água do solo pela evaporação, atenuando consequentemente as mudanças bruscas de temperatura (Matos, 2008).

A biomassa do café pode ter utilização alimentícia ou industrial. Assim como a casca, o óleo da biomassa do café é outra fonte de bioenergia e pode ser extraído utilizando diversos solventes, originando produtos com diferentes quantidades de aromáticos e ceras. Usualmente, o óleo de café industrializado é obtido pelo método de prensagem dos grãos. Atualmente, foram avaliados novos métodos para extração do óleo, visando a ampliação no resultado da técnica: extração supercrítica e extração com etanol comercial (Freitas; Garcia; Lago, 2001).

O agronegócio cafeeiro gera uma grande quantidade de resíduos a partir da sua colheita, beneficiamento e processamento, o que torna fundamental o reaproveitamento da biomassa. A adubação orgânica reduz a adubação química e quanto maior a decomposição dos restos vegetais e quanto mais ativa a formação de substâncias intermediárias de decomposição, tanto maior e mais benéfico será o efeito sobre a estrutura do solo (Fernandes et al., 2013).

Entre as fontes de matéria orgânica usadas na adubação orgânica do cafeeiro, a palha de café é a mais disponível e econômica. Cada saca de café produzida gera em torno de 50 a $60 \mathrm{~kg}$ de palha, que pode ser aplicada na planta e ainda entrar na fabricação de compostos, quando misturada com os estercos (Matiello et al., 2010).

No caso da cafeicultura no município de Barra do Choça a casca do café é aproveitada pela digestão anaeróbia onde o decomposto orgânico gerado é usado como biofertilizante nas próprias lavouras, algumas vezes sendo misturada ao esterco bovino e na maioria delas é usada sozinha como adubo. Essa técnica promove a diminuição de custos com adubação química além de ser uma alternativa limpa e renovável.

\section{Conclusão}

Após a colheita do fruto, o café é direcionado para o beneficiamento, esse processo gera uma grande quantidade de resíduos, a palha do café. Os restos de colheita e lavouras se dispostos de modo inadequado provocam a poluição e degradação dos solos e águas. A pesquisa mostrou o potencial bioenergético dos resíduos provenientes do beneficiamento da biomassa cafeeira uma vez que o aproveitamento da biomassa cafeeira é feito através de processos biológicos de digestão anaeróbica e fermentação quando volta para lavoura como adubo.

Usos modernos da biomassa oferecem um leque bastante amplo de alternativas para diminuir a dependência de combustíveis fósseis, atenuar emissões de gases do efeito estufa e promover desenvolvimento econômico sustentável.

A pesquisa revela a importância do uso do composto da biomassa do café, a qual tem sido cada vez mais empregada como fonte de matéria orgânica proporcionando grandes resultados. A casca proveniente da produção rural é utilizada na compostagem e essa biomassa retorna para a lavoura como adubo orgânico, promovendo uma grande economia no que diz respeito à diminuição de aditivos químicos e sustentabilidade no meio rural.

Contudo, com o presente estudo foi possível constatar que a biomassa cafeeira se constitui uma importante fonte bioenergética e que a disponibilidade do resíduo proveniente do seu beneficiamento viabiliza a sua utilização como fonte de nutrientes e por consequência acarreta na redução na adubação mineral do cafeeiro com características singulares que dá origem ao café gourmet.

Por fim, uma das estratégias de valorização do café é fazê-lo conhecido pelo seu modo de produção, qualidade e 
procedência. As características bióticas a abióticas favoráveis, além das técnicas manejo tornam a pesquisa relevante do ponto de vista acadêmico e social, assim, pretende-se estudar futuramente as características que influenciam o sucesso do agronegócio cafeeiro a fim de oportunizar a visibilidade da cafeicultura regional.

\section{Agradecimentos}

Aos proprietários da Fazenda, Valéria Vidigal da Cruz Brito e Gianno de Oliveira Brito, por contribuir ricamente para o sucesso desta pesquisa.

\section{Referências}

Andrade, M. C. de. (1994) O desafio ecológico: utopia e realidade. São Paulo: Editora Hucitec.

Bacelar, A. C. B. et al. (2020) Análise do potencial de indicação geográfica (IG) para o Café de Vitória da Conquista/Ba. REVISTA INGI, v. 4, p. 875-888 Brasil. (2019). Panorama das cidades. Instituto Brasileiro de Geografia e Estatística (IBGE).

Brasil. (2019). Estatísticas econômicas da agricultura e pecuária. Instituto Brasileiro de Geografia e Estatística (IBGE).

Fernandes, A. L. T. et al. (2013) Redução da adubação mineral do cafeeiro arábica com a utilização de palha de café. Viçosa, MG: SBICafé.

Ferraz, A. E. (2001) O urbano em construção: Vitória da Conquista - um retrato de duas décadas. Vitória da Conquista: Edições UESB.

Ferreira, L. T.; Santos, J. (2019) Safra mundial do ano-cafeeiro 2018-2019 atinge 174,5 milhões de sacas. Brasília, DF: Embrapa. Notícias.

Freitas, S. P.; Garcia, T. N.; Lago, R. C. A. (2001) Green coffee oil extraction with ethyl alcohol. In: LIPIDEX SUDAMERICA, Asaga, dmg, Buenos Aires.

Gil, A. C. (2010) Como elaborar projetos de pesquisa. 5. ed. São Paulo: Atlas.

Lima, D. R. (2010) Café \& Saúde. Porto Alegre: Expansão.

Matiello, J. B. (2016) Palha de café deve ser aplicada, não amontoada. Revista Cafeicultura, Rio Paranaíba, MG.

Matiello, J. B. et al. (2010) Cultura do café no Brasil: manual de recomendações. Rio de Janeiro; Varginha: Fundação Procafé.

Matos, A. T. de. (2008) Tratamento de resíduos na pós-colheita do café (residues disposal in coffee post-processing). In: BORÉM, F. M. (ed.). Pós-colheita do Café (coffee post processing). Lavras, MG: Editora UFLA. p. 161-2018.

Nova, L. (2010) Café, a saga de um herói. Arte e Café! Do Planalto de Vitória da Conquista para o Mundo. Ilustração Valéria Vidigal. Salvador: Contexto e Arte Editorial Ltda.

Orsini, R. dos R. (2012). Estudo do aproveitamentodo resíduo da lavoura cafeeira como fonte de biomassa na produção de hidrogênio. 142 f. Tese (Doutorado em Ciências na Área de Tecnologia Nuclear - Materiais) - Universidade de São Paulo, São Paulo.

Pereira A. S. et al. (2018). Metodologia da pesquisa científica. [e-book]. Santa Maria. Ed. UAB/NTE/UFSM. 